\title{
ERRATA
}

\section{- Volume 6 Number 3}

a) Page 162. In the title headings, the affiliation of Rajendra S. Garud ${ }^{2}$ and Vidya $\mathbf{S}$. Kharat ${ }^{2}$, instead of "'Bharati Vidyapeeth Dental College and Hospital, Pune, India", it must be "Department of General Anatomy and Histology, Bharati Vidyapeeth Deemed University Medical College and Hospital, Pune, India".

b) Page 164, the titles "Prof. Jennifer McBride (U.S.A. - Response to Garaud-Sharma)" and "Prof. Subramaniam Krishnan (Malaysia - Response to Garaud-Sharma)", they have to be written as "Prof. Jennifer McBride (U.S.A. - Response to GarudSharma)" and "Prof. Subramaniam Krishnan (Malaysia - Response to GarudSharma)" 